\title{
Coombs Negative Hemolytic Anemia of Unknown Origin in Pregnancy
}

\section{Sunday Alfred Dominico ${ }^{1 *}$, Mubarakali Janmohamed ${ }^{3}$, Alex Magesa ${ }^{2}$, Hyasinta Jaka ${ }^{3}$, Peter F Rambau ${ }^{4}$ and Anthony N Massinde}

${ }^{1}$ Department of Obstetric and Gynaecology, Catholic University of Health and allied Sciences, Tanzania

${ }^{2}$ Department of Haematology, Muhimbili National Hospital, Tanzania

${ }^{3}$ Department of Internal Medicine, Catholic University of Health and allied Sciences, Tanzania

${ }^{4}$ Department of Pathology and Forensic Medicine, Catholic University of Health and allied Sciences, Tanzania

\begin{abstract}
Hemolytic anemia is very common during pregnancy especially in malaria endemic areas and it is usually an autoimmune condition. Coombs negative or idiopathic hemolytic disease during pregnancy is very rare and it has not yet been described in sub-Saharan countries.

A 34-year-old grand-multiparous woman was referred at our facility at a gestation age of 22 weeks with features of severe anemia in pregnancy, and a history of receiving a blood transfusion (seven units). Several investigations including a Coomb's test were done. However, there were hardly any derangements, except for initial low hemoglobin. Coombs negative haemolytic anaemia of unknown origin was the final concluded diagnosis. She was treated with a course of glucorticoids, hematenics and a total of 36 units of blood transfusion. She finally delivered a premature baby at 35 weeks of gestation. She recovered completely during puerperium and was discharged the seventh day postpartum with a hemoglobin of $10 \mathrm{~g} / \mathrm{dl}$. She was lost to follow up.
\end{abstract}

Coombs Negative Hemolytic Anemia in pregnancy is likely to respond to blood transfusions in conjunction with glucocorticoid therapy.

Keywords: Coombs negative; Hemolytic anemia; Pregnancy

\section{Background}

Hemolytic Anemia is very common during pregnancy especially in malaria endemic areas [1]. It often associated with Tropical Splenomegaly Syndrome (now commonly known as Hyper-Reactive Malarial Splenomegay), which is an autoimmune phenomenon that follows episodes of malaria in the past [2]. Very few cases of Coombs Negative Hemolytic Anemia have been reported in literature [3,4]. This condition has not yet been described in Sub-Saharan Africa; hence we are presenting the first such case.

\section{Case Report}

A 34-year-old grand multiparous Tanzanian woman, at 22 weeks gestation, was referred from a nearby health facility due to difficulty in breathing, awareness of heart beats, and easy fatigability for over a period of one month. She denied a history of bleeding, or ruptures of membranes, and has perceived fetal movements normally. Her past gynecologic and obstetric history was significant for a history of six previous vaginal deliveries and a Caesarean section in her last childbirth. She also gave a history of a spontaneous abortion (of a five months pregnancy) after her last childbirth, the cause of which was not established. She received seven units of blood (with no improvement) before being referred to our centre.

She denied a history of using any medications prior to illness. Family and social history was unremarkable for bleeding disorders or a history of recurrent blood transfusions.

On physical examination; she was noted to be pale and mildly jaundiced with a bilateral pitting pedal edema. There was no sternal tenderness; neither were there any skin lesions or peripheral lymphadenopathy.

Respiratory findings revealed bibasilar crackles. Her cardiovascular assessment showed a pulse rate of 78 beats per minute, a blood pressure of $110 / 80 \mathrm{mmHg}$, and a functional ejection systolic murmur at the apex.

Her abdomen was distended with a uterine fundus equivalent to 24 weeks gestation and a sub-umbilical midline incision scar. Hepatosplenomegaly was noted. The fetal heart rate was 134 beats per minute detected by a pinnard fetoscope.

Investigations were done and the following are the results; Hemoglobin level on admission was $2.76 \mathrm{~g} / \mathrm{dl}$.

Blood group "B”, Rhesus positive.

Blood slide was negative for malarial parasites.

Her stool sample was negative for parasites and occult blood.

Urine dipstick was negative for leucocytes, red blood cells and schistosome ova.

Complete Blood Count showed hemoglobin of $4.9 \mathrm{~g} / \mathrm{dl}$, packed cell volume (PCV) 16.8\%, Mean Cell Volume (MCV) 87.0 fl, Mean Cell Hemoglobin $(\mathrm{MCH}) 25.7$ pg, Mean Cell Hemoglobin Concentration (MCHC) $29.5 \mathrm{gr} / \mathrm{dl}$, White Blood Cell (WBC) count of $3.5 \times 10^{9} / \mathrm{l}$, with normal differentials. Platelet count (PLT) was $149 \times 10^{\%} / 1$, and Reticulocyte Count was $1.2 \%$.

Total Bilirubin was $69.22 \mathrm{umol} / \mathrm{l}$, direct bilirubin 21.56umol/l, Lactate Dehydrogenase (LDH) 140 IU/L. Serum levels of Creatinine and Liver Transaminases were within normal range.

The Coombs Test and Rheumatoid Factor were negative.

*Corresponding author: Sunday Alfred Dominico, Department of Obstetric and Gynaecology, Catholic University of Health and allied Sciences, P.O Box 1374 Mwanza, Tanzania, E-mail: sundomy@yahoo.com

Received February 04, 2012; Accepted March 07, 2012; Published March 09 2012

Citation: Dominico SA, Janmohamed M, Magesa A, Jaka H, Rambau PF, et al. (2012) Coombs Negative Hemolytic Anemia of Unknown Origin in Pregnancy. $J$ Blood Lymph 2:103. doi:10.4172/2165-7831.1000103

Copyright: (C) 2012 Dominico SA, et al. This is an open-access article distributed under the terms of the Creative Commons Attribution License, which permits unrestricted use, distribution, and reproduction in any medium, provided the original author and source are credited. 
The Peripheral Blood Smear showed spherocytes.

The Bone Marrow aspirate showed leucocytosis with normal erythroid and myeloid precursors (Figure 1).

An initial obstetric ultrasound scan revealed a single live fetus in utero with a biparietal diameter of $63 \mathrm{~mm}$ equivalent to $(25 \mathrm{weeks} \pm 15$ days), abdominal circumference of $208 \mathrm{~mm}$ equivalent to ( 25 weeks \pm 15 days), femur length of $45 \mathrm{~mm}$ (24weeks \pm 15 days), the estimated fetal weight was 788 grams \pm 118 grams and the Gestation Age (GA) was estimated to be 25 weeks with an amniotic fluid index of $12 \mathrm{~cm}$. The placenta was located high anteriorly. Sonography of the abdomen was significant for mild splenomegaly.

A later scan at 28 weeks of gestation age revealed an estimated average gestation age of 28 weeks \pm 2 days. Scan at GA of 33 weeks showed an estimated fetal weight of $2.1 \mathrm{~kg}$ with an amniotic fluid index of $13 \mathrm{~cm}$.

She was started on daily Blood transfusions for several weeks with no improvement of her hematocrit. A decision was then made to start her on oral Prednisolone. The hemoglobin started to increase with each unit of blood transfused and she gradually became free of symptoms. She entered labour at 35 weeks of gestation and her hemoglobin was 9 $\mathrm{g} / \mathrm{dl}$ by then. She gave birth to a premature female baby of $2.2 \mathrm{Kg}$ whose APGAR score was 7 and 10 at the 1 st and 5 th minute respectively.
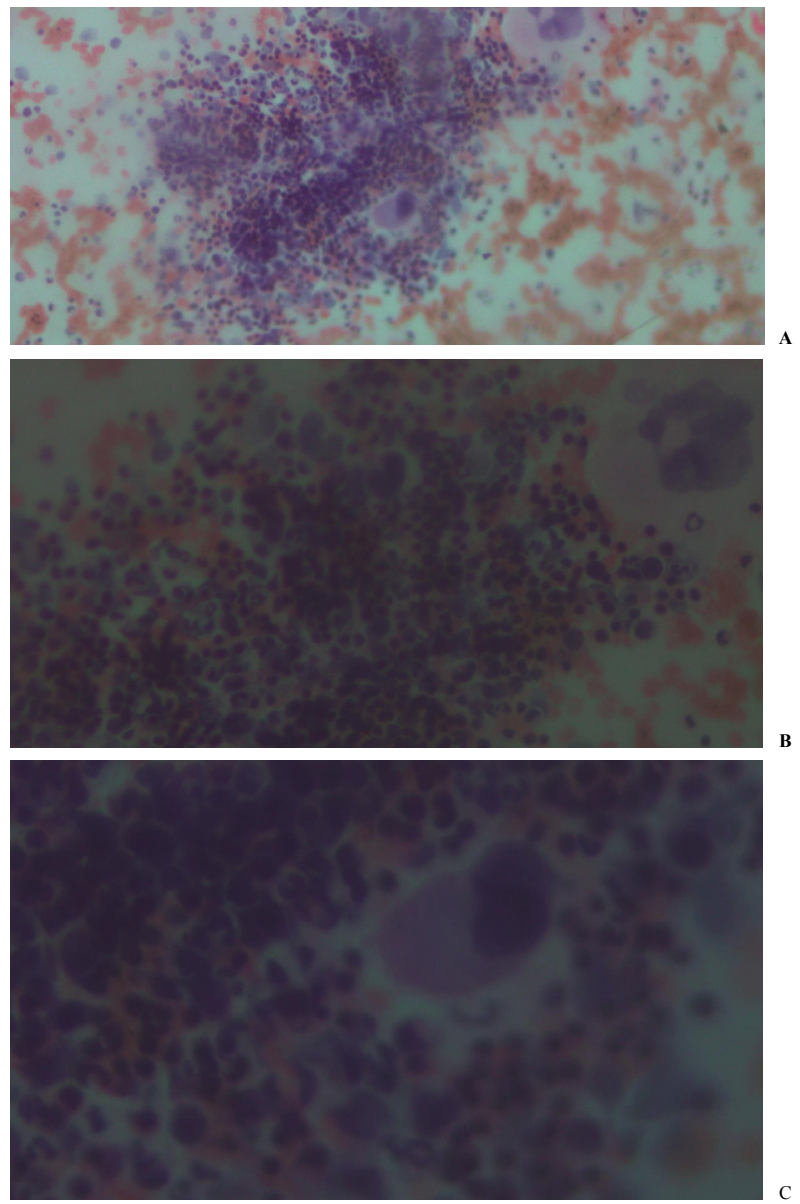

Figure 1: Bone marrow aspirate cytology slides as viewed by light microscope at various magnifications, $a(\times 10), b(\times 20)$ and $c(\times 40)$.
The patient was re-evaluated 5 days after delivery and all biochemical tests had returned to normal. The hemoglobin level increased to $10 \mathrm{~g} / \mathrm{dl}$, and the baby was doing fine. The mother and child were both discharged after a week. From Admission to delivery, this patient had received a total of 36 units of Blood. Unfortunately she was lost to follow-up.

\section{Discussion}

Anemia is one of the leading causes of maternal and perinatal deaths in pregnancy and puerperium [5-8]. Hemolysis is one of the rare several causes of severe anaemia in pregnancy worldwide [6,7].

In malaria endemic areas, hemolytic anemia can be prevalent during pregnancy, and the mechanism is thought to be related to an autoimmune response resulting into a phenomenon called the Tropical Splenemegaly Syndrome (TSS), currently referred to as Hyperactive Malarial Splenomegaly $[1,2,9]$. Patients will usually present with profound anemia, jaundice, a massive splenomegaly and pancytopenia with recurrent infections [2,9]. These features were present in our patient, however, a negative coombs test and the absence of massive splenomegaly and pancytopenia proved otherwise [9].

Coombs Negative Hemolytic Anemia (Idiopathic Hemolytic Anemia) is very rare in this population and its management is unclear Although the patient presented with typical features of hemolytic anemia, other causes of anemia must be ruled out. Anemias may have a multifactorial cause at times $[1,10]$. A blood smear is useful to exclude malaria or even Kala-Azar while a stool analysis is used to exclude parasitic causes. Peripheral blood smear and a bone marrow aspirate/ biopsy are important in ruling out myeloproliferative disorders. Complete Blood Counts (CBCs) are useful in excluding other similar conditions such as Evans Syndrome which is characterized by thrombocytopenia and autoimmune hemolysis [11]

As previously stated, management of such patients is challenging and controversial with scarce literature on the topic $[3,12]$. Some authors preferred steroid therapy, the mechanism being unclear $[3,13]$. Additionally, the role of splenectomy is also unclear as this was used in some cases related to autoimmune hemolytic disorders [2].

Multiple blood transfusion and iron supplements appeared to be an important part of the treatment [14]. Whether pregnancy has any role to play in the etiology remains unclear, however, the fact that this patient improved at the end of her pregnancy cannot be denied. A similar scenario can be seen for autoimmune related hemolysis during pregnancy, this has a better maternal outcome and usually resolves during puerperium $[3,4,12,15,16]$.

The Preterm labour and a low birth weight are among the reported complications of severe anaemia in pregnancy [14,17]. Maternal outcome is very unpredictable if the pregnant patient is allowed to go into labour with severe anemia $[5,18]$. Anemia may severely affect fetal outcome, hence serial obstetric ultrasound were done to monitor intrauterine growth $[5,18,19]$.

\section{Conclusion}

Severe anemia in pregnancy requires a tireless diagnostic and treatment approach if optimum maternal-fetal outcome are to be realized. Idiopathic Hemolytic Anemias, including those with a negative Direct Antiglobulin Test, respond to gluco-corticoid therapy. Blood transfusion is mandatory in cases of severe anemia in pregnancy with unknown or known causes to improve maternal and fetal outcome. 
Citation: Dominico SA, Janmohamed M, Magesa A, Jaka H, Rambau PF, et al. (2012) Coombs Negative Hemolytic Anemia of Unknown Origin in Pregnancy. J Blood Lymph 2:103. doi:10.4172/2165-7831.1000103

Page 3 of 3

\section{Competing Interests}

"The author(s) declare that they have no competing interests".

\section{Authors' Contributions}

"SD received the patient and did initial work-up, did literature review, wrote the initial manuscript and reviewed all other subsequent manuscripts. JM and $\mathrm{HJ}$ were consulted and involved in management of this patient including obtaining biopsy, both did literature review and revised the manuscripts. AM and ANM were consulted for management of this patient and contributed to review of literature. PR performed the histological examination of the bone marrow, and contributed in writing the manuscript. All authors read and approved the final manuscript".

\section{References}

1. Ghosh K, Ghosh K (2007) Pathogenesis of anemia in malaria: a concise review. Parasitol Res 101: 1463-1469.

2. Tesfamariam A, Zekarias Y, Tekle A (2009) Tropical Splenomegaly Syndrome in a pregnant woman: A good response and prognosis to splenectomy. JEMA 4.

3. Celalettin C, Zahit B, Hulki MS, Aybin Ö, Ceyhan C, et al. (2000) Pregnancy Induced Coombs' Negative Hemolytic Anemia. Adü Týp Fakültesi Dergisi 1: 43-45.

4. Katsuragi S, Sameshima H, Omine M, Ikenoue T (2008) Pregnancy-induced hemolytic anemia with a possible immune-related mechanism. Obstet Gynecol 111: $528-529$.

5. Kalaivani K (2009) Prevalence \& consequences of anaemia in pregnancy. Indian J Med Res 130: 627-633.

6. Balarajan Y, Ramakrishnan U, Ozaltin E, Shankar AH, Subramanian SV (2011) Anaemia in low-income and middle-income countries. Lancet 378: 2123-2135.

7. Guidotti RJ (2000) Anaemia in pregnancy in developing countries. BJOG 107: 437-438.
8. Marchant T, Schellenberg JA, Nathan R, Abdulla S, Mukasa O, et al. (2004) Anaemia in pregnancy and infant mortality in Tanzania. Trop Med Int Health 9: 262-266.

9. Michael E, Robert D, Andrew B, Wilkinson R (2008) Tropical spenomegaly syndrome Oxford Handbook of Tropical Medicine London, Oxford University Press.

10. Muhangi L, Woodburn P, Omara M, Omoding N, Kizito D, et al. (2007) Associations between mild-to-moderate anaemia in pregnancy and helminth, malaria and HIV infection in Entebbe, Uganda. Trans R Soc Trop Med Hyg 101: 899-907.

11. Lefkou E, Nelson-Piercy C, Hunt BJ (2010) Evans' syndrome in pregnancy: a systematic literature review and two new cases. Eur J Obstet Gynecol Reprod Biol 149: 10-17.

12. Sharma P, Sthapit $R$ (2008) Unexplained hemolytic anemia of pregnancy: Case report with review of related literature. NJOG 3: 49-50.

13. Tsai YC, Chang JM, Chang JC, Changahien CC, Chen PH, et al. (1994) Idiopathic autoimmune hemolytic anemia during pregnancy. J Formos Med Assoc 93: 328-331.

14. Sifakis S, Pharmakides G (2000) Anemia in pregnancy. Ann N Y Acad Sci 900 125-136.

15. Craig GA, Turner RL (1955) A case of symptomatic haemolytic anaemia in pregnancy. Br Med J 1: 1003-1005.

16. Baumann R, Rubin H (1973) Autoimmune hemolytic anemia during pregnancy with hemolytic disease in the newborn. Blood 41: 293-297.

17. Lao TT, Pun TC (1996) Anaemia in pregnancy--is the current definition meaningful? Eur J Obstet Gynecol Reprod Biol 68: 53-58.

18. Malee M (2008) ACOG Practice Bulletin No. 95: anemia in pregnancy. Obstet Gynecol 112: 201-207.

19. Rogerson SJ (2009) Malaria in pregnancy and the newborn. Adv Exp Med Bio 659: 139-152. 